\title{
The Impact of the Accuracy of Terrain Surface Data on the Navigation of Off-Road Vehicles
}

\author{
Josef Rada, Marian Rybansky *(D) and Filip Dohnal \\ Department of Military Geography and Meteorology, University of Defence, 66210 Brno, Czech Republic; \\ josef.rada@unob.cz (J.R.); filip.dohnal@unob.cz (F.D.) \\ * Correspondence: marian.rybansky@unob.cz
}

Citation: Rada, J.; Rybansky, M.;

Dohnal, F. The Impact of the Accuracy of Terrain Surface Data on the Navigation of Off-Road Vehicles. ISPRS Int. J. Geo-Inf. 2021, 10, 106. https://doi.org/10.3390/ijgi10030106

Academic Editor: Wolfgang Kainz

Received: 16 December 2020

Accepted: 18 February 2021

Published: 24 February 2021

Publisher's Note: MDPI stays neutral with regard to jurisdictional claims in published maps and institutional affiliations.

Copyright: (C) 2021 by the authors. Licensee MDPI, Basel, Switzerland. This article is an open access article distributed under the terms and conditions of the Creative Commons Attribution (CC BY) license (https:/ / creativecommons.org/licenses/by/ $4.0 /)$.

\begin{abstract}
Current soil and surface data are not detailed enough to obtain accurate analyses of cross-country movement. The reason for the research presented in this article was the absence of a methodology for the synthetic assessment of the influence of the terrain surface on the movement of military vehicles. The study is based on analyses of data and information sources of soils and surface conditions primarily with the aim to determine their reliability, availability and precision when used for analyses of terrain traversability by off-road vehicles. The key method to achieve the set objective is the employment of tractive charts of military vehicles and utilized coefficients, the coefficient of rolling resistance and the coefficient of adhesion. Input data and information is tested with a comparative method of cross-country movement analyses. Conversion of soil and surface types to tractive chart coefficients is currently not optimal. For the most part, evaluation of soil type is very inaccurate with a wide range of possible values. Results of the analysis propose developing a methodology of evaluating surface and soils for vehicle traversability.
\end{abstract}

Keywords: cross-country movement; tractive chart; soil database; military vehicles

\section{Introduction}

The form and results of terrain analyses rely significantly on the quality of the input databases used. Digital elevation models covering information of slope gradient are a reliable global source of data. Characteristics of surface and soil information are a less accurate data source with limited availability. Nevertheless, this kind of information is key for detailed analysis of cross-country movement (CCM). The research focuses on determination of accuracy, availability and overall quality of soil and surface cover data and information, and testing of the detail and suitability of the current and most frequently employed methods of information processing for CCM analyses. Terrain trafficability analyses are based on mathematical and physical models evaluating the influence of the terrain surface on the movement of off-road vehicles. There is a great amount of literature focused on evaluating the movement possibilities of military, rescue, forestry, agricultural, space or special unmanned ground vehicles (UGVs). Terrain trafficability models for military applications are the focus of research activities of selected military institutions.

The U.S. Army Engineer Research and Development Center (ERDC) has a long history of developing the North Atlantic Treaty Organization (NATO) Reference Mobility Model. Ahlvin and Haley [1] in the "NATO reference mobility model" (NRMM) described the calculation of the influence of individual factors on the movement of military vehicles. Procedural Guide for Preparation of Cross-Country Movement analysis is described in Reference [2], and Shoop [3] and Shoop et al. [4,5] characterize individual elements of the terrain in terms of determining the possibility of movement of off-road vehicles. Baylot et al. describe the standards for ground vehicle mobility in Reference [6]. The operational forecasts model of trafficability is described by Mason et al. [7]. Frankenstein and Koenig analyze soil compaction during the annual seasons in Reference [8]. In relation to the above publications, the study presented in this article represents another possibility of how to 
include, in the complex model of mobility of off-road vehicles, the joint influence of slope inclination and resistance of movement given by soil types.

The Next-Generation NATO Reference Mobility Model (NG-NRMM) development is published in Bradbury et al. [9]. Particularly, the last-mentioned publication was used in the current research as it utilizes the same mechanism of CCM analysis, which is based on tractive charts and their coefficients.

Models of terrain trafficability by military vehicles are also the subject of research conducted at the University of Defense in Brno. A variety of publications and studies at the university served as a basis for the research conducted in this article. Rybansky analyzed the impact of geographical factors on cross-country movement in References [10-23]. Among other factors, these publications describe in detail the calculation of traction forces required to overcome the slopes of the terrain. There is also the calculation of the limit longitudinal and transverse slopes of the slope for overturning and sliding vehicles when moving in rugged terrain. Hubacek et al. described the soil measurement in the Czech Republic in terms of trafficability in Reference [24]. Talhofer et al. analyzed the influence of spatial database quality on modelling of vehicle movement in terrain in References [25,26]. These analyses are not based on traction curves and terrain resistance coefficients but instead use the results of correlation relationships between the slope and vehicle speed measured during physical field testing of vehicles to calculate vehicle deceleration. In Reference [27], Nohel et al. deal with the calculation of the shortest off-road vehicle route. The theory of vehicle motion based on traction curves is described by Vala and Braun in Reference [28] and Vala and Žalud in Reference [29]. The evaluation of dynamics of vehicle movement in terrain is published by Hlaváček in Reference [30]. Hubáček et al. and Mertová deal with the modelling of geographic and meteorological effects on vehicle movement focusing on soil conditions and penetrometry in References [31-34]. Dohnal et al. calculate the influence of microrelief shapes on the maneuverability of terrain vehicles in Reference [35]. Hofmann et al. [36] deal with the creation of cross-country movement maps using vehicle deceleration coefficients due to terrain elements. Hošková-Mayerová et al. analyzed the influence of weighting geographical factors on the results of multicriteria analysis in solving spatial analyses [37]. Stodola et al. proposed the novel hybrid metaheuristic algorithm for the Dynamic Travelling Salesman Problem (DTSP) in Reference [38]. The methods described in this article follow-up on the above studies and further extend them to cartographic analyses, and images, of how terrain limits the movement of selected vehicles.

Other possible approaches for analysis of traversability, not directly utilized in this article, are described in the following papers. Studies dealing with the automatic creation of cross-country movement maps are published by Pokonieczny $[39,40]$ or Pokonieczny and Rybansky [41]. Heštera and Pahernik described the physical-geographic factors of terrain trafficability of military vehicles according to Western World methodologies in Reference [42]. Ciobotaru suggests the semi-empiric algorithm for assessment of the vehicle mobility in Reference [43]. Vantsevich et al. focus on the technical aspects of terrain vehicles and their mobility estimation in Reference [44]. An overview of terra-mechanical models analyzing the influence of soils on the movement of off-road vehicles is summarized by He et al. [45].

Other publications which were not specifically used in this study, but bring interesting conclusions, focus on analysis of mobile robots' navigation, and autonomous vehicles' terrain traversability and three-dimensional (3D) traversability. Such studies include Iagnemma and Dubowsky [46], Halatci et al. [47] and Reina et al. [48], focused on planetary rovers' motion planning in rough terrain. Reina et al. describe the possibilities of using the trinocular stereovision for ground detection in agriculture in Reference [49]. Bellone et al. analyze the 3D traversability awareness for rough terrain mobile robots [50]. Braun et al. [51] describe the visual terrain traversability estimation using a combined slope/elevation model. The entire body of research on the cross-country movement topic is solicited by the Grand Challenge, which was launched by the Defense Advanced Research Projects Agency (DARPA) in 2003 to spur innovation in UGV navigation. The goal of the 
challenge was to develop an autonomous robot capable of traversing unrehearsed off-road terrain. An example of a publication created with the support of DARPA is Thurn et al. [52].

The terrain passability model described in this article is based on the study of the mutual influence of terrain slope and soil characteristics on the movement of selected military off-road vehicles. The analysis presented in this article primarily utilizes the key findings of the papers of Vala and Braun [28], Rybansky [10-23], Hlaváček [30] and Bradbury et al. [9]. Analysis of both soil databases and surface information is performed by the testing of tractive charts of various wheeled and tracked vehicles and comparing the results of cross-country movement analysis. The proposed changes of methodology and data processing may significantly improve results of analyses of a vehicle's traversability.

\section{Methodology}

The studies presented in the introduction of the article are mostly focused on the influence of particular terrain factors on the analysis of off-road vehicles' movement. This is mainly the influence of the selected geographical objects: terrain, soils, water, vegetation, or meteorological conditions. The methodology described in this article enables the assessment of the synthetic influence of terrain slopes, and soil properties, on the movement of military vehicles using available data from geographical databases. The validity of this methodology is also reinforced in its outputs, in the form of terrain traversability maps, or direct inputs to the navigation systems of military vehicles. Accuracy and reliability of source data and information are defined with a comparison of results of cross-country movement analyses, in other words, a comparison of resulting passable and impassable areas for different surface conditions.

The consecutive steps of the utilized methodology in the study are as follows (and displayed in Figure 1):

- Study of soil and surface cover databases and information, utilizing their parameters.

- Preparation of tractive charts of vehicles, including the determination of different coefficients of adhesion and coefficients of rolling resistance for various possible surface conditions in the selected area, Bačetín, gathered from the databases.

- Calculation of the maximum gradient for each selected vehicle for different surface conditions.

- Calculation of CCM analyses for different conditions-a map analysis (both best- and worst-case scenario).

- Determination of the influence of soil databases and surface information accuracy to the results of CCM analyses-a diagram analysis (a comparison of the results for each database).

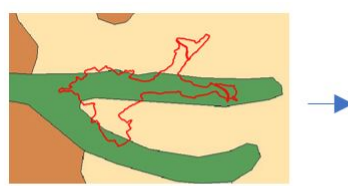

Analyses of soil databases

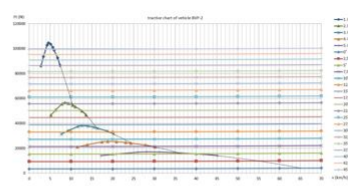

Preparation of tractive charts

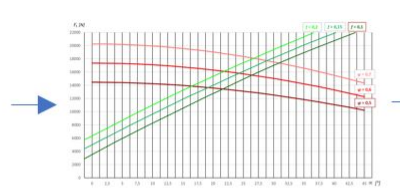

Calculation of maximum gradient

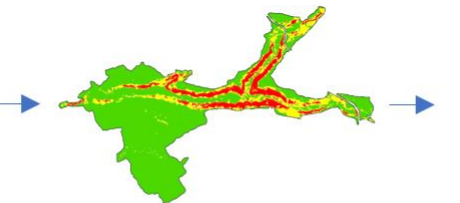

CCM

map analysis

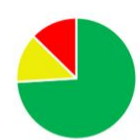

Conclusion

Diagram analysis

Figure 1. Flow chart of the study methodology.

\subsection{Selection of the Testing Area}

The first matter to solve during the research was choosing a representative location at which the findings would be verified. The area selected for analysis of data with tractive charts is a forest situated in the Eastern Bohemia near the town Dobruška. This location was selected due to complete availability of all required databases. Additionally, the area displays both the structure and placement suitability for all types of terrain analyses. It represents a sample of landscape and surface cover which is primarily within the Czech 
Republic, it is an undulating landscape partially covered with forestry of a primarily coniferous nature. The locality (coordinates 50.307 N, 16.217 E), Bačetín forest, is situated in North-East Czech Republic, its size is $2.5 \times 1.5 \mathrm{~km}$. It is a plateau split into two distinct parts: the southern extent predominantly consists of a sandy-clayey soil type with a mean slope gradient of $5.2^{\circ}$, while the northern extent of the forest is formed along a narrow valley, with primarily alluvial soil and a mean slope gradient of $11.7^{\circ}$. These soils and gradients are prevailing in the Czech Republic.

\subsection{Selection of Military Vehicles for Testing}

The second goal was to identify a balanced sample of military vehicles with division to wheeled and tracked types. The final selection consisted of personnel wheeled vehicle Land Rover Defender 110 (LRD 110), wheeled truck Tatra 815 (T815 $6 \times 6$ drive) and an infantry armored tracked vehicle Bojové vozidlo pěchoty 2 (BVP-2). The technical parameters of these vehicles are given in Table 1 . Each of these vehicles have distinct characteristics and driving performance. Testing of vehicle features was not conducted in the terrain and leans only on theoretical analysis. Local conditions were verified during site surveys in the area Bačetín.

Table 1. Technical parameters of selected vehicles.

\begin{tabular}{cccc}
\hline Vehicle & LRD 110 & T815 6 $\times \mathbf{6}$ & BVP-2 \\
\hline Length $(\mathrm{mm})$ & 4680 & 9650 & 6735 \\
\hline Width $(\mathrm{mm})$ & 1800 & 2545 & 2975 \\
\hline Height $(\mathrm{mm})$ & 2100 & 3370 & 2060 \\
\hline Total weight $(\mathrm{kg})$ & 3500 & 15,000 & 13,000 \\
\hline Max. speed $(\mathrm{kph})$ & 130 & 85 & 65 \\
\hline Engine power $(\mathrm{kW})$ & 83 & 270 & 220 \\
\hline Max. adhesive force $(\mathrm{kN})$ & 28 & 225 & 35 \\
\hline Climbability $\left(^{\circ}\right)$ & 30 & 30 &
\end{tabular}

\subsection{Forces Affecting Movement of Vehicles}

As one of the most used analyses within military geography, the analysis of CCM first requires the accurate establishment of surface conditions. In order to do that, all major forces which influence movement of vehicles over terrain have to be defined. The basis of a drive is the tractive force, which defines the speed and the ability of a vehicle to move over terrain [30]. Counter forces for the tractive force represent conditions of the surface which is often contained as characteristics within databases. Major counter forces are the rolling resistance and the resistance of slope gradient. Counter forces are analyzed in detail in Reference [28]. The last individual composition of movement is the adhesive force. It determines a limit of slipping in connection with a state of surface and a slope gradient. All these forces and surface data have been tested on tractive charts of selected vehicles. Each force is defined mainly with a coefficient: the coefficient of adhesion and the coefficient of rolling resistance. The research focuses on comparing the accuracy of these coefficients to the results of CCM analyses. The tractive chart method is innovative due to its clear map and diagrammatic depiction of possible range of outputs of CCM analyses. The range is set when using basic accuracy (maximum and minimum value) of coefficient of adhesion and the coefficient of rolling resistance.

\subsection{Coefficient of Deceleration by Effect of Soil Factor}

The coefficient of deceleration by effect of soil factor (marked $C_{3}$ ), albeit not directly incorporated into tractive chart formulas, has its own influence on CCM, mainly represented by speed corrections. Analysis of this coefficient was not one of the initial goals. For the purpose of the study, quality of the surface (soil $C_{31}$, vegetation cover $C_{32}$ and roughness 
$C_{33}$ ) had to be ascertained. The Defense Mapping Agency (DMA) method, described in the Procedural Guide for Preparation of DMA Cross-Country Movement Overlays [2], was selected as the appropriate method for evaluation of $C_{31}$ coefficient. The other two coefficients have been determined as a combination of a vector data study and a site survey of surface in the selected area. Their basic values are described in Reference [10]. The DMA method, with coefficient $C_{3}$, shows how insufficient surface information and databases are when used for detailed CCM analysis in small-scale areas, such as the studied one.

\section{Theoretical Basis and Processing of Data}

3.1. Definition of the Most Influential Forces Acting on the Movement of a Vehicle

3.1.1. Tractive Force

The tractive force is calculated using technical parameters of a vehicle. It can also be defined as in Formula (1), where tractive force is equal to the sum of the forces of resistance [30]:

$$
F_{T}=F_{f}+F_{s}+F_{i}+F_{v}+F_{H}[N]
$$

where $F_{f}$ is the rolling resistance, $F_{S}$ is the resistance of gradient, $F_{i}$ is the inertia resistance, $F_{v}$ is the resistance of air and $F_{H}$ is the resistance of a trailer. Formula (1) determines the minimum tractive force required for a vehicle to start moving [30]. The inertia resistance, the resistance of air and the resistance of a trailer can be omitted due to their insignificant influence. The rolling resistance and the resistance of slope gradient represent major components of resistance forces. Along with the adhesive force, they are the most important parts of the study. It is, for the most part, the analysis of the influence of the coefficient of rolling resistance and the coefficient of adhesion on a tractive chart, and hence it indirectly influences the outputs of CCM analyses.

\subsubsection{Rolling Resistance}

The coefficient of rolling resistance represents quality of surface (e.g., firm or muddy) and differs for wheeled and tracked vehicles [30]. Formula (2) shows calculation of the rolling resistance:

$$
F_{f}=G f \cos \alpha[N]
$$

where $G$ is the gravitation force of a vehicle, $f$ is the coefficient of rolling resistance and $\alpha$ is the longitudinal gradient. The specific table values of coefficient $f$ are presented, for example, in Reference [14].

\subsubsection{Resistance of Gradient}

The resistance of longitudinal gradient has a direct influence on what extent of slope gradient a vehicle can overcome. It is calculated with Formula (3):

$$
F_{s}=G \sin \alpha[N]
$$

\subsubsection{Adhesive Force}

The maximum tractive force $F_{T \max }$ is limited by the adhesive force $F_{a d}, F_{T \max }=F_{a d}$. The adhesive force is calculated with Formula (4):

$$
F_{a d}=G \varphi \cos \alpha[N]
$$

where $\varphi$ is the coefficient of adhesion. Coefficient of adhesion varies according to a construction of a tire (shape, material, etc.) and a type of tracks [19]. It differs for wheeled and tracked vehicles and a type of surface. The specific table values of coefficient $\varphi$ are published in Reference [14]. 


\subsection{Definition of Coefficient of Deceleration by Effect of Soil Factor}

The second method to conduct CCM analysis is with coefficient of deceleration. The coefficient of deceleration by effect of soil factor is calculated as a combination of three different factors [10]:

$$
C_{3}=\prod_{i=1}^{3} C_{3 i}, i=1,2,3
$$

where $C_{3}$ is the coefficient of deceleration by effect of soil factor, $C_{31}$ is the coefficient of deceleration by effect of soil type (sort) factor, $C_{32}$ is the coefficient of deceleration by effect of factor of vegetation cover (sort of plants) and $C_{33}$ is the coefficient of deceleration by effect of surface roughness factor.

The coefficient of deceleration has a direct influence on speed of a vehicle. If the coefficient equals 1 , the vehicle continues with unchanged speed. If the coefficient equals 0 , the vehicle stops at the analyzed section. The vehicle is slowed down when the coefficient is in the range from 0 to 1 . The resulting reduced speed of the vehicle depends on a type and quality of surface. It can be calculated from maximum speed $v_{\max }$ using Formula (6):

$$
v=v_{\max } C_{3}\left[m s^{-1}\right]
$$

The coefficient of deceleration by effect of soil type factor $\left(C_{31}\right)$ can be determined by two methods. The first contemplated model was the GeoSl AČR model (Geographical service of the Armed forces of the Czech Republic). It is specified by sort of soils and conditions of precipitation, though results are overly simplifying. It is based on the project methodology of delimitation imtraversability of soils [53]. The DMA model is calculated from technical parameters of a vehicle and also in compliance with a division of soils of the Unitary classification of soils standardized in NATO. It classifies soils with the Rated Cone Index [9]. It is a more detailed model than GeoSl AČR, however, with similar drawbacks, the only precise values coming into calculation are technical parameters of vehicles. The variables sort of soils and a level of moisture are inaccurate and can take a wide range of values. Thus, accuracy of methods used in the analysis is of the same importance as accuracy of input data. Overall, the highest level of uncertainty resides in determination of moisture of soil. Output coefficients of both methods were tested in the study to analyze the impact of their accuracy to results of CCM analysis.

Both the coefficient of deceleration by effect of factor of vegetation cover, and the coefficient of deceleration by effect of surface roughness factor, are determined by expert evaluation from basic information in vector databases and from further verification of the terrain [30]. The coefficients were assigned the same values, 0.9. Combinations of all three surface coefficients of deceleration for different surface types located in the area Bačetín were employed in the tractive chart analysis (included in comparison in Table 2).

\subsection{Processing of Database of Soils}

The fundamental source of all covering detailed soil data in the Czech Republic is the map of soils, in scale 1:50,000, managed by the Czech geological service. The region of Eastern Bohemia is covered with a set of raster maps based on mapping produced in the 1950s. This data is provided directly as the Web Map Service online. In a comparison with vector data (newer mapping covering other parts of the Czech Republic), raster data has lower accuracy. Another available source of information is The Special Purpose Database of Soils. This database utilizes synthetic map of soils 1:200,000. It consists of a dominant component of a soil type and attached characteristics of granulometric composition [54]. The database is further described and analyzed in Reference [10].

Databases of soils study can be found in Reference [34]. The map of soils in scale $1: 50,000$ is the basis for determination of a soil type used in terrain analyses. The database is relatively outdated, most of the characteristics were captured 60 years ago. Nonetheless, due to the fact that these features are in most part invariable, the state of the database 
still fits to conditions in the terrain. Figure $2 a, b$ depicts the influence of a lower resolution of raster data in the area Bačetín selected for testing. Actual positions, in comparison with the data, have shifted in some cases by more than 50 meters. The second studied soil database, The Special Purpose Database of Soils, was rated as significantly generalizing in comparison with the Map of soils 1:50,000. Even though it comprises the soil type/granulometric composition conversion, it still lacks in detail, accuracy and, in some cases, reliability [32]. The map of soils 1:50,000 was designated as more suitable for further analyses and processing.

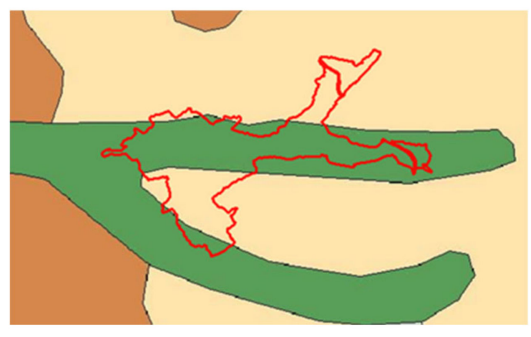

(a)

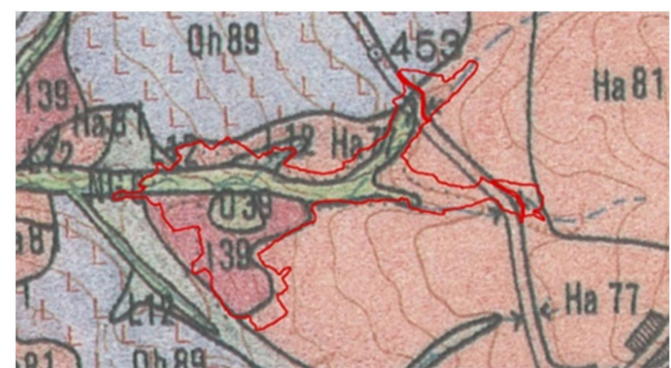

(b)

Figure 2. (a). The map of soils 1:50,000 from earlier map-ping (1950s) with the selected area of testing: shifted po-sition (and lower accuracy) is located near the stream and the boundary of the forest (e.g., I39 soil type does not fit with the edge of the forest edited from national vector databases-red line). (b). The Special Purpose Database of Soils is a generalizing soil situation in the selected area, Bačetín.

Another drawback for precise utilization of the Map of soils 1:50,000 is a conversion of a soil type from the Taxonomical Classification System of soils in the Czech Republic [55] into evaluation of soils according to a granulometric composition. Not all of the present soils were directly conversed with a unique sort of soil (granulometric composition). Described properties of soils in the taxonomical system may lead to equivocal results during the conversion. In consideration of a relatively small difference of characteristics of dual output soils, range of variation could be omitted, thus, only one sort of soil was selected. Most of the cases concerning this duality are clayey and clayey-sands types of soils. All the types of soils (taxonomical classification) located in the area Bačetín are listed in Table 2, including their conversion to a sort of soils (granulometric composition).

Table 2. The conversion list of types of soils in the Taxonomical Classification System (translated into WRB2006-the World Reference Base [55]) to a sort of soils according to a granulometric composition.

\begin{tabular}{ccc}
\hline Code & Type of Soils & Sort of Soils (Granulometric Composition) \\
\hline I39 & Albeluvisols & Clayey \\
O39 & Stagnosols & Clayey sands \\
NG6 & Fluvisols & Floodplain clayey \\
L12 & Phaeozems & Clayey \\
HA77 & Cambisols & Clayey sands \\
QH89 & Calcic leptosols & Sandy clay \\
\hline
\end{tabular}

The converted results were then used to assign values to the characteristics of surface in the area Bačetín. Resulting values of the coefficient of deceleration, the coefficient of rolling resistance and the coefficient of adhesion are displayed in Table 3. Input information is comprehensive and easily accessible, nevertheless, accuracy of output coefficients is low. Elemental accuracy for $C_{3}$ is set 0.1 , for $f$ is 0.05 and for $\varphi$ is 0.1 (basic values of distinguishable soils). Basic values of evaluated coefficients for soil and surface types in Table 3 are taken from Reference [14]. 
Table 3. Resulting characteristics of the tested area Bačetín used in the analysis of cross-country movement with tractive charts. Four sorts of soils are located in the area.

\begin{tabular}{ccccccccccc}
\hline Vehicle & \multicolumn{3}{c}{ LRD 110 } & \multicolumn{3}{c}{ T815 6 $\times \mathbf{6}$} & \multicolumn{3}{c}{ BVP-2 } \\
\hline $\begin{array}{c}\text { Sort of } \\
\text { Soil/Coefficient }\end{array}$ & $\boldsymbol{C}_{\mathbf{3}}$ & $\boldsymbol{f}$ & $\boldsymbol{\varphi}$ & $\boldsymbol{C}_{\mathbf{3}}$ & $\boldsymbol{f}$ & $\boldsymbol{\varphi}$ & $\boldsymbol{C}_{\mathbf{3}}$ & $f$ & $\boldsymbol{\varphi}$ \\
\hline Sandy clay & 0.79 & 0.10 & 0.5 & 0.44 & 0.10 & 0.5 & 0.81 & 0.15 & 0.7 \\
Clayey sands & 0.81 & 0.10 & 0.5 & 0.66 & 0.10 & 0.5 & 0.81 & 0.15 & 0.7 \\
Clayey soil & 0.73 & 0.10 & 0.5 & 0.40 & 0.10 & 0.5 & 0.81 & 0.15 & 0.7 \\
Floodplain clayey soil & 0.73 & 0.20 & 0.5 & 0.40 & 0.20 & 0.5 & 0.81 & 0.20 & 0.7 \\
\hline
\end{tabular}

Other information regarding surface type, including surface vegetation cover, does not exist in any national database, including forestry databases. Current information has to be gathered in the terrain. The digital elevation model, fifth generation, the most detailed elevation database in the Czech Republic, served as subsidiary data to verify local slope conditions. This elevation model has elementary density of points, 1 per 1 square meter. General characteristics of surface were acquired from national vector databases-digital terrain model 1:25,000 [56] and ZABAGED (The Fundamental Base of Geographic Data of the Czech Republic) [57]. These databases are the only sources of versatile information sources that include areal surface cover. In order to reach accurate CCM analysis results, any field data is required for soil characteristic validation and vegetation cover analysis. This step could be improved by using satellite imagery and image processing techniques.

\subsection{Setting of Limits for Cross-Country Movement Analysis}

From the perspective of $\mathrm{CCM}$, the evaluated area, Bačetín, is divided into passable (GO), hardly passable (SLOW GO) and impassable terrain (NO GO), which signifies limit parameters for a vehicle to reach (e.g., maximum slope gradient) [10]. These values are taken from a tractive chart. One of the charts used in the study is introduced in Figure 3.

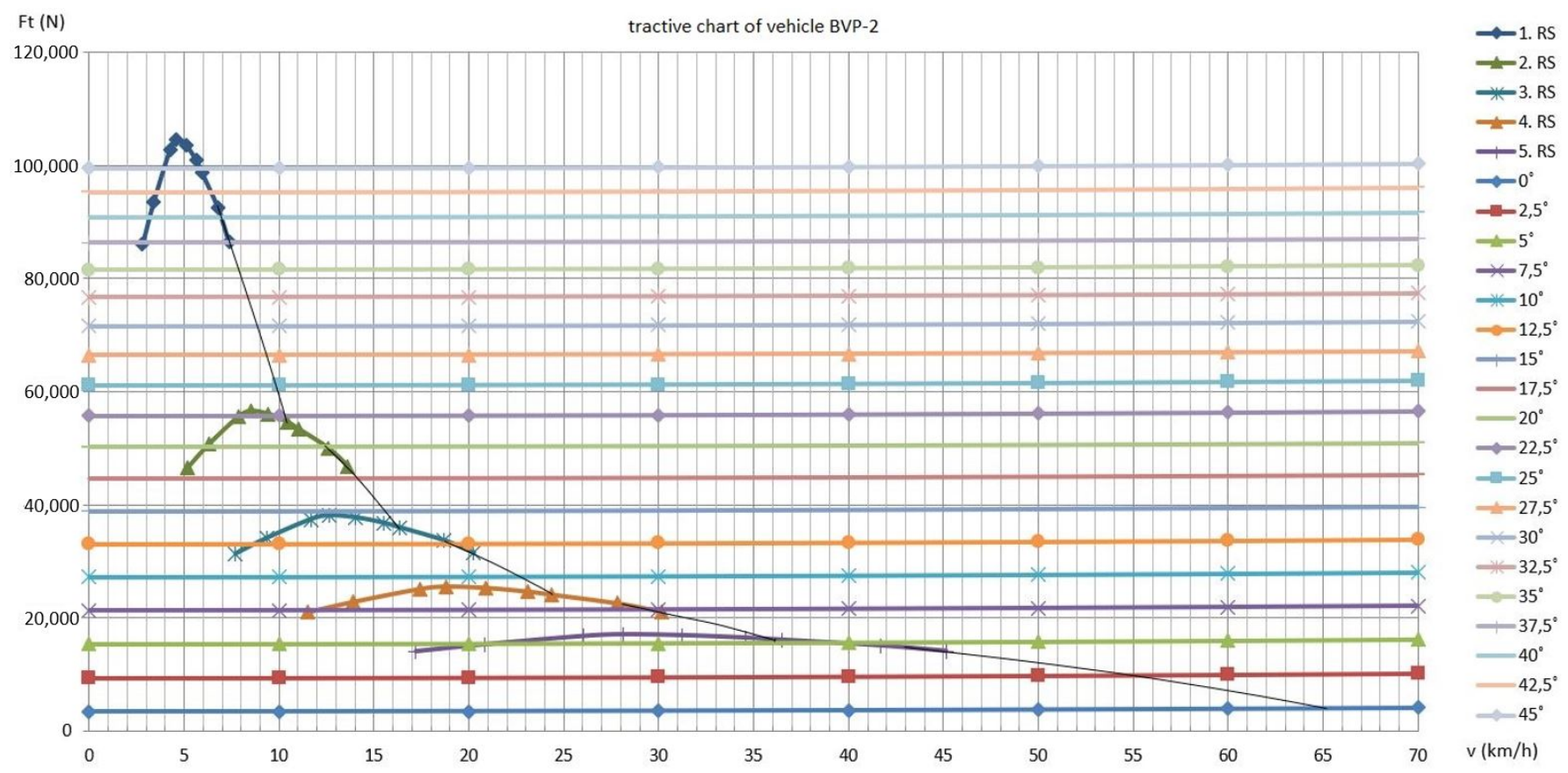

Figure 3. The tractive chart of the infantry armored vehicle BVP-2 used in the analysis of data and information of surface. Source data were used from Reference [30], RS curves in the legend-a gear level, other curves—a gradient. Values are calculated for conditions in the area Bačetín. 
The upper limit of gradient for impassable terrain displayed in Table 3 is defined with the maximum tractive force of a vehicle for first gear. This limit value may be reduced according to height of the adhesive force. A limit value for hardly passable terrain cannot be directly calculated. It was determined for the purpose of the study from a point on a tractive chart where a vehicle changes gear from second to first (also representing sizeable loss of speed). Given the different characteristics of soils for each tested vehicle, the resulting values read from a tractive chart for CCM analysis are shown in Table 4. Due to a minimum difference between sandy-clays, clayey-sands and clayey soil, further analysis was based only on two values: the floodplain clayey soil and other sorts of soils.

Table 4. GO and SLOW GO limit slope gradients for tested vehicles in the selected area. The first three sorts of soils were merged into one to simplify further data analysis.

\begin{tabular}{ccccccc}
\hline $\begin{array}{c}\text { CCM Maximum } \\
\text { Slope Gradient }\left({ }^{\circ}\right)\end{array}$ & $\begin{array}{c}\text { LRD 110 } \\
\text { NO GO }\end{array}$ & $\begin{array}{c}\text { LRD 110 } \\
\text { SLOW } \\
\text { GO }\end{array}$ & $\begin{array}{c}\text { T815 } \\
\text { NO GO }\end{array}$ & $\begin{array}{c}\text { T815 } \\
\text { SLOW } \\
\text { GO }\end{array}$ & $\begin{array}{c}\text { BVP-2 } \\
\text { NO GO }\end{array}$ & $\begin{array}{c}\text { BVP-2 } \\
\text { SLOW } \\
\text { GO }\end{array}$ \\
\hline Sandy clays & 21.82 & 16.17 & 21.80 & 12.08 & 28.80 & 15.30 \\
Clayey sands & 21.82 & 16.17 & 21.80 & 12.08 & 28.80 & 15.30 \\
Clayey soil & 21.83 & 16.21 & 21.80 & 12.08 & 28.81 & 15.31 \\
Floodplain clayey soil & 16.74 & 10.27 & 16.70 & 6.25 & 26.57 & 12.20 \\
\hline
\end{tabular}

\section{Results of Data Analyses}

Evaluation of traversability can be processed with two methods: with the coefficient of deceleration calculated from the DMA model or the GeoSl AČR model, analyzed in References $[9,18,24]$, and with the coefficient of adhesion and the coefficient of rolling resistance, analyzed in References [29,30].

Both methods require a tractive chart to evaluate the maximum slope gradient and the maximum speed which a vehicle is capable of reaching. Definitions and calculations of CCM with these methods are studied in References [14,30]. Impact of accuracy of the methods of analysis of traversability is described in the following sections.

\subsection{Influence of Coefficient of Deceleration to Parameters of CCM}

Basic accuracy of the $C_{3}$ coefficient can be defined as $\delta C_{3}=0.1$. Assigned values of speed calculated from the tractive charts of the vehicles representing this accuracy are shown in Table 5. Selected basic accuracy of deceleration of the soil factor does not have a significant influence on accuracy of a maximum reachable speed (taken conditions of the selected area). Data with this accuracy can still be used for detailed CCM analysis. A ratio of range of variation to overall value of speed is approximately the same, different influence of various tested vehicles on calculated accuracy of speed was not proven. Vehicle LRD 110 has higher speed range of variation due to in general higher reachable speed. Range of variation used in Tables 4-6 is calculated using Formula (7):

$$
\sigma_{\omega_{i}}=\omega_{\text {imax }}-\omega_{\text {imin }}
$$

where $\sigma$ is range of variation, $\omega_{i}$ is a variable (speed or gradient), $\omega_{\text {imax }}$ is maximum value of the variable when using lower value of tested coefficient $\left(C_{3}, f, \varphi\right)$ and $\omega_{\text {imin }}$ is minimum value of the variable when using upper value of tested coefficient $\left(C_{3}, f, \varphi\right)$. 
Table 5. Relation of basic accuracy of the coefficient of deceleration of the soil factor $\delta C_{3}=0.1$ and range of variation of maximum reachable speed and percentual ratio of range of variation of speed to a respective maximum speed of a vehicle. The test was conducted with measurement (calculation) of parameters of a tractive chart of selected vehicles for two values, $C_{3}=0.7$ and $C_{3}=0.8$, for two points on a tractive curve, the maximum limit value of passable terrain and maximum value of terrain passable with restrictions. Results are calculated from conditions in the selected area Bačetín.

\begin{tabular}{|c|c|c|c|c|}
\hline Vehicle & $\begin{array}{c}\text { Range of Variation of } \\
v_{\max } \\
\text { NOGO }\left(\mathrm{kmh}^{-1}\right)\end{array}$ & $\begin{array}{c}\text { Ratio of Range of } \\
\text { Variation to Total } v_{\max } \\
\text { NOGO (\%) }\end{array}$ & $\begin{array}{c}\text { Range of Variation of } \\
v_{\max } \\
\text { SLOWGO }\left(\mathrm{kmh}^{-1}\right)\end{array}$ & $\begin{array}{l}\text { Ratio of Range of } \\
\text { Variation to Total } v_{\max } \\
\text { SLOWGO }(\%)\end{array}$ \\
\hline LRD 110 & 2.5 & 13.3 & 3.3 & 13.1 \\
\hline T815 & 0.9 & 13.3 & 1.6 & 13.7 \\
\hline BVP-2 & 0.8 & 12.3 & 1.6 & 13.6 \\
\hline
\end{tabular}

Table 6. Impact of basic accuracy of coefficient of adhesion $\delta \varphi=0.1$ to range of variation of maximum gradient and maximum speed of the selected vehicles and ratio of the range of variation to their total values. Results are calculated from conditions in the selected area, Bačetín.

\begin{tabular}{|c|c|c|c|c|}
\hline Vehicle & Gradient $\left(^{\circ}\right)$ & Ratio (\%) & Speed $\left(\mathrm{kmh}^{-1}\right)$ & Ratio (\%) \\
\hline LRD 110 & 4.57 & 17.3 & 2.9 & 15.2 \\
\hline T815 & 4.58 & 17.3 & 0.9 & 13.5 \\
\hline BVP-2 & 4.21 & 14.6 & 0.7 & 9.3 \\
\hline
\end{tabular}

\subsection{Influence of the Coefficient of Adhesion to Parameters of CCM}

The coefficient of adhesion has substantial impact on CCM parameters of vehicles, the maximum slope gradient and the maximum speed. The maximum tractive force is higher than adhesive force for all tested vehicles, so that the level of NO GO slope gradient is set by the maximum adhesive force. Values of the test of coefficient of adhesion were extracted to overall in Table 6, which compares the influence of basic accuracy of coefficient of adhesion $\delta \varphi=0.1$ to respective values of maximum slope gradient and maximum speed of the selected vehicles.

Accuracy of determination of the coefficient of adhesion has the greatest influence with the vehicle LRD 110, the range of variation of maximum gradient is almost 5 degrees of the total maximum gradient. The biggest range of variations in speed, over $50 \%$ of absolute values, has T815. Greater range of variation is caused by lower reachable speed of T815 near NO GO gradients.

\subsection{Influence of the Coefficient of Rolling Resistance to Parameters of CCM}

The rolling resistance has a direct influence on determination of slope gradient value. The higher the coefficient is, the lower the gradient is reachable. Wheeled vehicles have lower coefficient of rolling resistance than tracked vehicles for the same type of surface. Whilst the adhesive force diminishes the reachable slope gradient of almost 10 degrees, the rolling resistance attains reduction of maximum gradient of 5 degrees. Basic accuracy of the coefficient of rolling resistance was set to 0.05 . The impact of this basic resolution is incorporated in Table 7.

Table 7. Influence of basic accuracy of the coefficient of rolling resistance $\delta f=0.05$ on range of variation of maximum slope gradient and maximum speed of selected vehicles and percentual values of the range of variation to their total values. Results are calculated from conditions in the selected area, Bačetín.

\begin{tabular}{ccccc}
\hline Vehicle & Gradient $\left(^{\circ}\right)$ & Ratio $(\mathbf{\%})$ & Speed $\left(\mathbf{k m h}^{-\mathbf{1}}\right)$ & Ratio $\mathbf{( \% )}$ \\
\hline LRD 110 & 2.77 & 17.03 & 0.85 & 4.70 \\
T815 & 2.73 & 19.23 & 0.60 & 25.67 \\
BVP-2 & 3.01 & 21.40 & 2.85 & 65.90 \\
\hline
\end{tabular}


Values of accuracy of maximum gradient for basic accuracy $\delta f=0.05$ are around 3 degrees for all tested vehicles. The coefficient of rolling resistance has a little influence on correction of speed. Reliability of range of variation of the coefficient is lower with low speed, e.g., ratio of range of variation of speed to absolute value of maximum speed of the vehicle BVP-2 is $65.9 \%$.

\subsection{Overall Results of CCM Analysis}

Outcomes of CCM analysis were evaluated by determining the possible range of variation between the best and the worst conditions set by the coefficient of adhesion and the coefficient of rolling resistance. Input values of $f$ and $\varphi$ are given by the conditions in the selected area, Bačetín. Results in Figure 4 display the tractive force needed to overcome the respective gradient with different values of the coefficients. Selected values represent plausible difference of surface conditions in the studied area and it is also based on the basic accuracy of the coefficient of adhesion and the coefficient of rolling resistance.

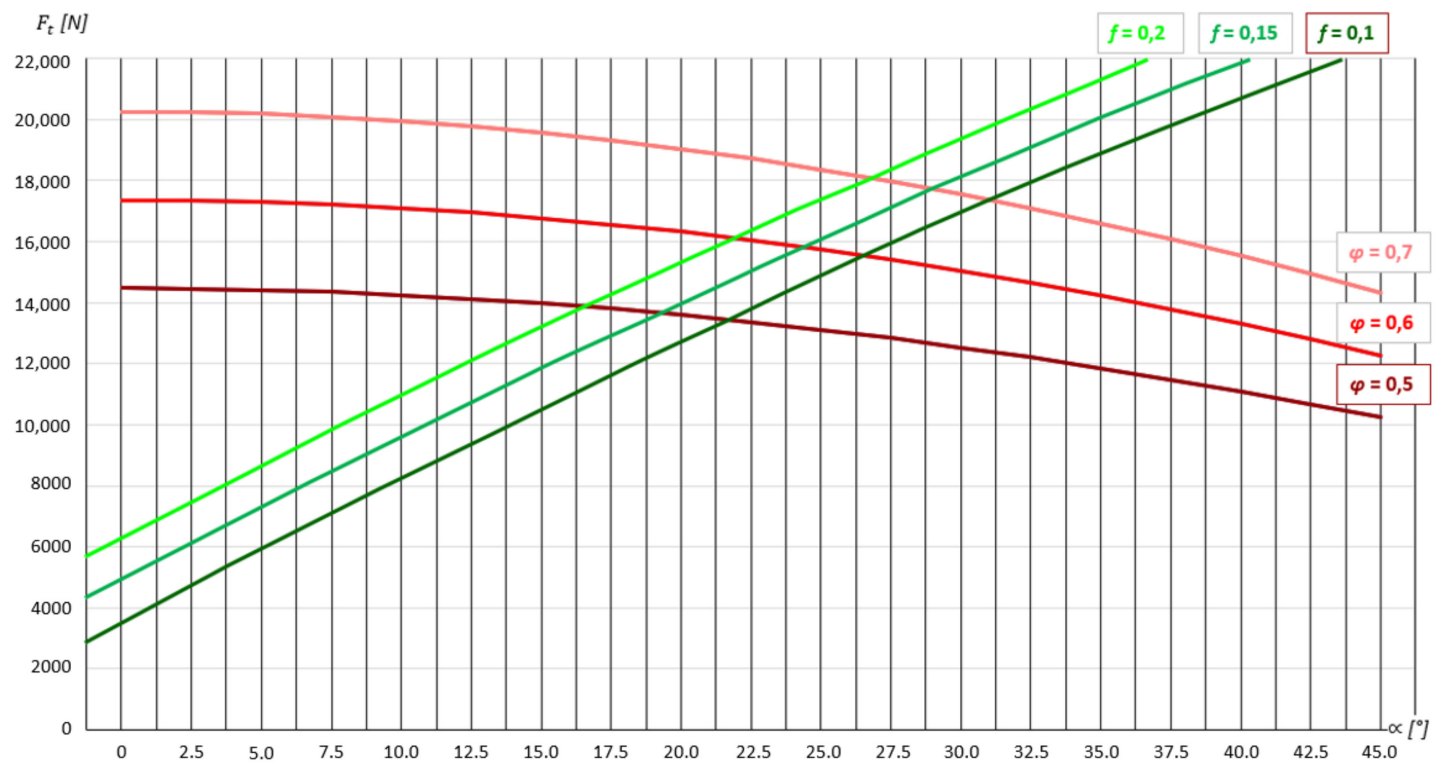

Figure 4. The analysis of influence of the coefficient of adhesion and the coefficient of rolling resistance to determination of the maximum reachable gradient for the vehicle LRD 110 in the area Bačetín. This comparison has been performed with the implementation of three values per each coefficient. Areas created by intersection of individual curves signifies uncertainty of determination of the maximum reachable gradient.

Points of intersection in Figure 4 define maximum reachable gradient for the vehicle LRD 110. Extent of gradient values shows that inaccurate determination of characteristics of surface has a substantial influence on capability of a vehicle to pass through a specific section. The resulting values are as follows:

- The variant of the best rated traversability: $f=0.1$ and $\varphi=0.7-$ maximum reachable gradient is up to $30.89^{\circ}$ and the limit for hardly passable terrain is $16.17^{\circ}$.

- The variant of the worst rated traversability: $f=0.2$ and $\varphi=0.5$-maximum reachable gradient is up to $16.74^{\circ}$ and a limit for hardly passable terrain is $10.27^{\circ}$. The area calculated from CCM analysis is displayed in Figure 5.

- The variant of the best rated traversability: $f=0.1$ and $\varphi=0.7-$ GO 86.6\%, SLOW GO $13.1 \%$, NO GO $0.3 \%$.

- The variant of the worst rated traversability: $f=0.2$ and $\varphi=0.5-\mathrm{GO} 74.0 \%$, SLOW GO $13.2 \%$, NO GO $12.8 \%$. 
The results of comparison of CCM analysis are displayed in maps in Figure 5 in the form of raster analysis. Raster methods of vehicle mobility analysis in the terrain are also studied in References [19,39-41].

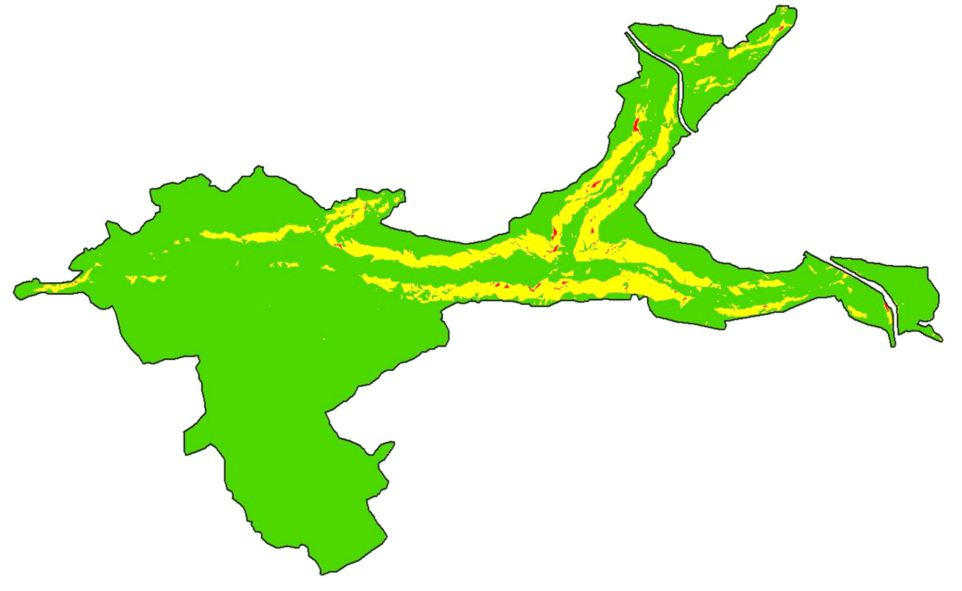

$\mathrm{okm}$ ratio of passable area

the best rated conditions

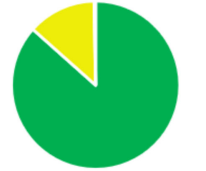

- $G O$ [ha]

"SLOWGO [ha]

- NOGO [ha]

(a)

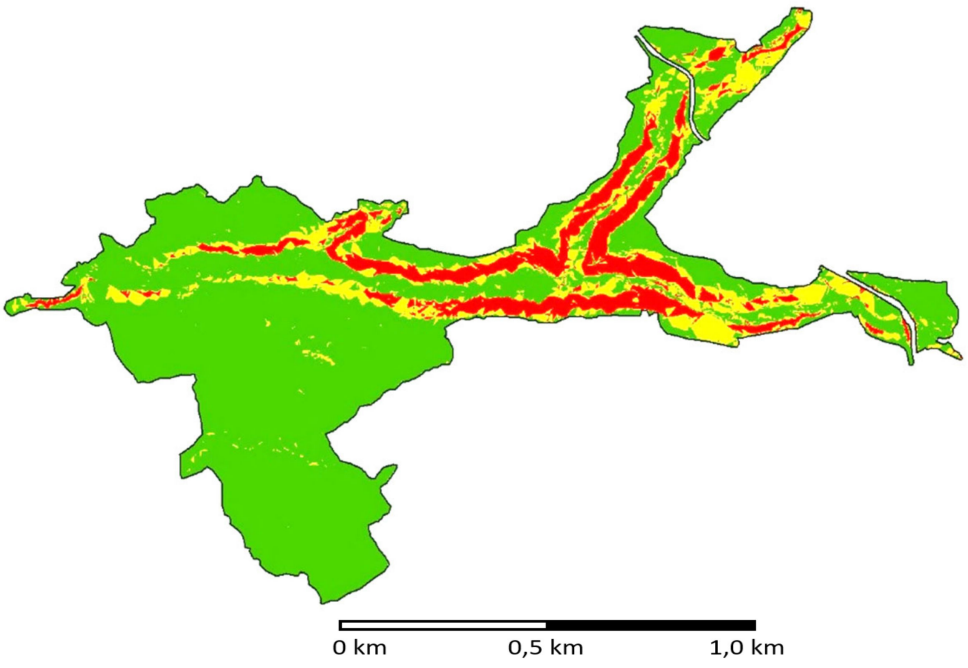

ratio of passable area

the worst rated conditions

(b)

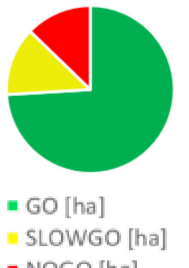

- NOGO [ha]

Figure 5. (a) The comparison of two variants of traversability in the selected area Bačetín for the vehicle LRD 110. The analysis consists of influence of gradient and soils. This figure represents the best rated traversability conditions, $f=0.1$ and $\varphi=$ 0.7. (b) The comparison of two variants of traversability in the selected area Bačetín for the vehicle LRD 110. This figure represents the worst rated traversability conditions, $f=0.2$ and $\varphi=0.5$. The difference in the evaluated impassable area shows the influence of uncertainty of surface classification. Maps of gradient were created from Digital Elevation Model 5th generation (DEM 5G).

\section{Discussion}

The analysis of quality of soil databases and information about surface was performed on the comparison of features of tractive charts. Reliability of the map of soils 1:50,000 is not high but still exceeds the Special Purpose Database of Soils, therefore, it is recommended as the primary database of soils usable for basic CCM analyses, also see Mertová [34]. The coefficient of deceleration by effect of soil factor, the coefficient of rolling resistance and the coefficient of adhesion have the biggest impact on accuracy of CCM data. Their analysis 
was based on the defining of specific points on a tractive chart, the limit for SLOW GO and NO GO slope gradient.

Influence of data to CCM analysis was already noticeable within the initial phase of finding a boundary for passable and impassable terrain. A value of NO GO terrain boundary in a tractive chart is determined with accuracy of the tractive force and the adhesive force. Whereas the tractive force is computed precisely from technical parameters of vehicles, the adhesive force is dependent on the accuracy of two parameters-slope gradient and the coefficient of adhesion. Accuracy of slope gradient is high due to using the detailed digital elevation model, fifth generation, available in the Czech Republic. Soil and surface conditions defining the value of the coefficient of adhesion are more difficult to determine. This makes analysis of CCM relatively inconsistent due to diverse data sources entering the analysis.

The coefficient of deceleration by effect of soil factor $C_{3}$ has a negligible influence on accuracy of slope gradient. On this aspect, it does not matter which model is utilized, whether the DMA or the GeoSl AČR model. More important is correct determination of conditions of terrain when coefficient of deceleration by effect of soil factor equals 0 , as it is the main asset of the GeSl AČR model [58]. The model GeoSl AČR can be considered as overly general, merging many types of soils and surface into only the small set of coefficients. The model DMA evaluates the group of soils with the Rated Cone Index (RCI), which is more elaborate than the Czech model, which is also the conclusion of Hubáček [32]. Though, in the end, everything depends on estimate of a moisture level of soil. A moist soil and a wet soil have noticeably different traversability characteristics for most types of soils. A major factor affecting the accuracy of the coefficient of deceleration by effect of soil factor is moisture of soils, and the influence of determination of sort of soils can be mostly omitted (when not knowing the exact level of moisture). For instance, only organic silt has a significant difference in results (RCI values are low in comparison with other sorts of soils), calculated also in Hlaváček [30]. Other significant external factors influencing output $\mathrm{CCM}$ analysis are temperature and precipitation values. They are partially represented by table values of studied coefficients which differ in various conditions.

The coefficient of deceleration by effect of soil factor has, on the other hand, a major influence on reduction of speed of vehicles. The faster the vehicle, the bigger the reduction of speed is. Wheeled vehicles have range of variation of speed up to $3 \mathrm{kmh}^{-1}$ and tracked vehicles up to $1 \mathrm{kmh}^{-1}$ (with set maximum speed in terrain $20 \mathrm{kmh}^{-1}$ and the basic accuracy of the coefficient $\delta C_{3}=0.1$ ). If speed is considered as a secondary variable (for the purpose of simplification of CCM analysis), the coefficient $C_{3}$ can be limited only to values 0 and 1 , without any wider loss of accuracy.

Influence of determination of surface conditions (soil type, etc.) to results of CCM analyses is significant. The difference of maximum gradient reachable by the vehicle LRD 110 between the best rated conditions, $f=0.1$ and $\varphi=0.7$, and the worst rated conditions, $f=0.2$ and $\varphi=0.5$, in the selected area Bačetín is over $14^{\circ}$. This range of variation is $46 \%$ of the maximum value of the gradient, which signifies unreliable results. In addition, difference of evaluated impassable area is, in total, $13 \%$, and over $50 \%$ in limited CCM analysis with the focus limited to the selected valley, which is in the middle of the area Bačetín, covering $25 \%$ of the area. Uncertainty in determination of surface conditions supersedes other aspects of CCM analyses (influence of gradient, forest, etc.) and must be solved as a major issue to improve results of analyses of traversability.

Results of analyses of the coefficient of adhesion indicate that accuracy of the adhesive force has a larger impact on wheeled vehicles than on tracked vehicles. Tracked vehicles reach higher adhesive force, thus, limit values of reachable gradient are also higher. The resulting range of variation of maximum gradient is bigger, yet it represents a smaller calculated area than for wheeled vehicles. Area of gradient in the range of $15^{\circ}-20^{\circ}$ (maximum for wheeled vehicles) is, in the studied territory Bačetín, much bigger than for gradient in the range of $20^{\circ}-25^{\circ}$ (maximum for tracked vehicles). Maximum gradient accessible for both wheeled and tracked vehicles is not defined with the maximum tractive force, but 
with the adhesive force. Basic accuracy of the coefficient of adhesion $\delta \varphi=0.1$, with surface conditions of the selected area Bačetín, influences determination of slope up to 5 degrees. This level of inaccuracy approves that the table values of soil and surface types, along with their level of moisture, have to be further divided into more classes. These classes should be evaluated separately for wheeled and tracked vehicles, and original values are used from Rybanský [14]. The proposed basic table accuracy of the coefficient of adhesion should be $\delta \varphi=0.05$, with the same limitation of range of values. For instance, tracked vehicles have range of $\varphi$ for sandy surface $\varphi=\langle 0.4,0.7\rangle$, which is overly large and must be divided into more specific conditions with a step of $\delta \varphi=0.05$ to get more accurate results of CCM analyses.

The rolling resistance has approximately the same influence on each tested vehicle. Basic accuracy of the coefficient of rolling resistance $\delta f=0.05$, with surface conditions of the selected area Bačetín, defines a 3 degrees range of variation in maximum slope gradient, and influence on maximum speed is minimal, up to $1 \mathrm{~km} / \mathrm{h}$. Fixed basic accuracy has a perceptible range of variation, therefore, the coefficient has to be elaborated into more classes, with more sorts of surface and levels of moisture, whilst concurrently unifying the list for wheeled and tracked vehicles. The suitable form would be a detailed list of surface and soil types (similar to RCI) with three variants of moisture. Furthermore, the list should be divided into wheeled and tracked vehicle values, potentially even to a more detailed division. With respect to the study and survey in the terrain, an important aspect would be further division of the table to wheeled vehicles among light personal wheeled types (LRD 110) and heavier wheeled truck types (T815). Preparation of such a table would require extensive testing of military techniques and vehicles in the terrain. By doing this research, accuracy of soil and surface databases and models would be significantly higher, followed by more reliable CCM analyses. Soil and surface databases may not be improved much currently, but their processing for the purpose of CCM analysis can be vastly developed.

The basic table accuracy of the coefficient of rolling resistance should be $\delta f=0.02$, with the same limitation of range of values. For example, wheeled vehicles have range of $f$ for wet clayey soils, $f=\langle 0.10,0.20\rangle$. Given the 3 degrees range of variation in maximum slope gradient for basic accuracy $\delta f=0.05$, this range (wet clayey soils) must be divided to more specific types with a max step of $\delta f=0.02$ in order to obtain more accurate results of CCM analyses.

The combined basic accuracy of surface conditions $\delta \varphi=0.05$ and $\delta f=0.02$ would increase accuracy of calculation of maximum gradient from 7 to 3 degrees. Respective division of table values of soil and surface types and their moisture level is still manageable under these circumstances (from current 25 surface types to approximately over 75 surface types). Further division with basic accuracy of surface conditions $\delta \varphi=0.01$ and $\delta f=0.01$ would significantly increase accuracy of calculation of maximum gradient to 1 degree. Nevertheless, this division is currently technically almost unfeasible with too many surface types to be tested in the terrain (with estimated number over 400 surface types). The measurements should also incorporate the influence of temperature and precipitation to characteristics of the surface. Incorporating actual conditions of the surface would substantially increase the accuracy of the CCM analysis.

The methodology for determining the impact of terrain surface parameters on the movement of military vehicles could, under certain conditions, be applied to other vehicles as well. Tensile force, adhesion coefficients and rolling resistance are decisive for the analysis of the movement of agricultural vehicles. These parameters change mostly after plowing and heavy rainfall. In addition to the parameters and technical parameters above, quality of elevation data has a significant effect for smaller vehicles, such as UGV and mobile robots (wheeled, tracked, combined). The smaller the dimensions of a vehicle, the greater demands on the accuracy and density of altitude data, see also References [46-50]. If an altitude model with record density of $1 \times 1 \mathrm{~m}$ is sufficient for tested military vehicles (with the dimensions given in Table 1), an altitude model with a point density in decimeters and an accuracy in centimeters will be required for smaller vehicles. 


\section{Conclusions}

The primary findings of the study show that the processing of soil and surface data and methods of CCM analyses are currently more important than the databases themselves. The primary issue is that information, and attributes in the studied databases, do not include essential data needed to improve the analyses. Furthermore, range of variation in determination of surface conditions calculated from tractive charts of the selected vehicles in the studied area, Bačetín, is significant. Parameters of tractive charts, the coefficient of adhesion and the coefficient of rolling resistance are reflective representants of surface conditions in general. Their table values are even more important than soil and surface databases. CCM analyses would be considerably improved with more detailed separate table values for wheeled and tracked vehicles for these two coefficients. The studied maximum gradient reachable by the vehicle LRD 110 is almost double for the best possible rated conditions compared to the worst rated conditions. This represents a range of variation of basic accuracy of coefficients representing the selected area. CCM analyses cannot be sufficiently reliable unless a more detailed system of rating of soils and surface is found. Future studies and researches should focus on introducing a suitable method of data processing in order to enhance CCM analyses, especially for small-scale areas, which represent the military tactical level of planning. Academic contributions of the study reside in the defining of values of a range of results of CCM analysis that military planners can expect from current surface information and databases in the representative area of the Czech Republic.

The authors of the article anticipate that further research would enable the improvement of the proposed methodology. It is predominantly the use of remote sensing methods to determine the characteristics of the terrain surface (determining the slopes of the terrain, soil moisture, soil temperature) and verifying these attributes by field measurements (tachymeter, penetrometer, bevameter). A necessary prerequisite for validation of these measurements is also a pedological laboratory analysis of soils, with a focus on determining moisture parameters and distribution characteristics of soil granularity. One of the possible solutions is also use of SENTINEL-2 data (thematic services or applying classification techniques). This could be an example for rapid land monitoring and land cover change mapping. Anyway, a field campaign is necessary to validate both remote sensing maps and CCM-retrieved conclusions.

Author Contributions: Conceptualization and methodology, Josef Rada and Marian Rybansky; validation, Josef Rada, Marian Rybansky and Filip Dohnal; writing the paper, Josef Rada and Marian Rybansky; original draft preparation, Filip Dohnal. All authors have read and agreed to the published version of the manuscript.

Funding: This research received no external funding.

Institutional Review Board Statement: Not applicable.

Informed Consent Statement: Not applicable.

Data Availability Statement: Not applicable.

Acknowledgments: This paper is a particular result of the defense research project DZRO K-210 NATURENVIR managed by the University of Defense in Brno, NATO-STO Support Project (CZEAVT-2019) and Specific research project 2019 at the department K-210 managed by the University of Defense in Brno.

Conflicts of Interest: The authors declare no conflict of interest. The funders had no role in the design of the study; in the collection, analyses, or interpretation of data; in the writing of the manuscript, or in the decision to publish the results.

\section{References}

1. Ahlvin, R.B.; Haley, P.W. NATO reference mobility model. In NRMM II User's Guide. TR GL-92-19, 2nd ed.; US Army Engineer Waterways Experiment Station: Vicksburg, MS, USA, 1992.

2. Monkhouse, F.J. Principles of Physical Geography, 8th ed.; Hodder and Stoughton: London, UK, 1975. 
3. DMA. Procedural Guide for Preparation of DMA Cross-Country Movement (CCM) Overlays; Defence Mapping School: Fort Belvoir, VA, USA, 1993.

4. Shoop, S. Terrain Characterization for Trafficability, CRREL Report 93-6; U.S. Army Corps of Engineers, Cold Regions Research \& Engineering Laboratory: Hanover, NH, USA, 1993; Available online: www.researchgate.net/publication/235013633 (accessed on 5 August 2020).

5. Shoop, S.A.; Affleck, R.; Collins, C.; Larsen, G.; Barna, L.; Sullivan, P. Maneuver analysis methodology to predict vehicle impacts on training lands. J. Terramech. 2005, 42, 281-303. [CrossRef]

6. Shoop, S.A.; Richmond, P.W.; Lacombe, J. Overview of cold regions mobility modeling at CRREL. J. Terramech. 2016, 43, 1-26. [CrossRef]

7. Baylot, E.A.; Gates, B.Q.; Green, J.G.; Richmond, P.W.; Goerger, N.C.; Mason, G.L.; Cummins, C.L.; Bunch, L.S. Standard for Ground Vehicle Mobility; U.S. Army Corps of Engineers: Vicksburg, MS, USA, 2005.

8. Mason, G.; Ahlvin, R.; Green, J. Short-Term Operational Forecasts of Trafficability; U.S. Army Corps of Engineers: Washington, DC, USA, 2001.

9. Frankenstein, S.; Koenig, G. Fast All-Season Soil Strength (FASST); Cold Regions Research and Engineering Laboratory: Hanover, NH, USA, 2004.

10. Bradbury, M.; Dasch, J.; Gonzalez-Sanchez, R.; Hodges, H.; Iagnemma, K.; Jain, A.; Jayakumar, P.; Letherwood, M.; McCullough, M.; Priddy, J.; et al. Next-Generation NATO Reference Mobility Model (NRMM) Development (Développement de la Nouvelle Génération du Modèle de Mobilité de Référence de l'OTAN (NRMM)); Dasch, J., Jayakumar, P., Eds.; NATO Science and Technology Organization: Neuilly-Sur-Seine, France, 2018.

11. Rybanský, M. Modelling of the Geographical Factors Influence on the Cross-Country Movement. Habilitation Thesis, Vojenska akademie, Brno, Czech Republic, 2002.

12. Rybanský, M. Effect of the geographic factors on the cross-country movement during military operations and the natural disasters. In Proceedings of the ICMT'07 International Conference on Military Technologies 2007, Brno, Czech Republic, 2-4 May 2007; pp. 590-596, ISBN 978-80-7231-238-2.

13. Rybanský, M.; Vala, M. Geographic conditions of military transport using roads and terrain. In Proceedings of the ICMT'09 International Conference on Military Technologies 2009, Brno, Czech Republic, 5-6 May 2009; p. 9, ISBN 978-80-7231-649-6 (978-80-7231-648-9 CD).

14. Rybanský, M.; Vala, M. Analysis of relief impact on transport during crisis situations. In Moravian Geographical Reports; Academy of Sciences of the Czech Republic: Prague, Czech Republic, 2009; Volume 17, pp. 36-43. ISSN 1210-8812.

15. Rybanský, M. The Cross-Country Movement-The Impact and Evaluation of Geographic Factors; CERM: Brno, Czech Republic, 2009; p. 113. ISBN 978-80-7204-661-4.

16. Rybansky, M.; Vala, M. Relief impact on transport. In Proceedings of the $\mathrm{ICMT}^{\prime} 09$ International Conference on Military Technologies 2009, Brno, Czech Republic, 5-6 May 2009.

17. Rybanský, M. The Cross-Country Movement-Modeling; University of Defence: Brno, Czech Republic, 2010; p. 100. ISBN 978-80-7204-717-8.

18. Rybanský, M. Modelling of the optimal vehicle route in terrain in emergency situations using GIS data. In Proceedings of the IOP Conference Series: Materials Science and Engineering, 2014 International Conference on Manufacturing, Optimization, Industrial and Material Engineering (MOIME 2014), Jakarta, Indonesia, 29-31 March 2014.

19. Rybanský, M. Soil trafficability analysis. In Proceedings of the International Conference on Military Technology Proceeding, ICMT'15, Brno, Czech Republic, 19-21 May 2015; pp. 295-299, ISBN 978-80-7231-976-3.

20. Rybansky, M.; Hofmann, A.; Hubacek, M.; Kovarik, V.; Talhofer, V. Modelling of cross-country transport in raster format. Environ. Earth Sci. 2015, 74, 7049-7058. [CrossRef]

21. Rybansky, M.; Dohnal, F. The impact of drainage on terrain vehicle movement. In Proceedings of the 19th International \& 14th European-African Regional Conference of the International Society for Terrain-Vehicle Systems, Budapest, Hungary, 25-27 September 2017; pp. 1-8, ISBN 978-1-942112-49-5.

22. Rybansky, M. Trafficability analysis through vegetation. In Proceedings of the 2017 International Conference on Military Technologies (ICMT), Brno, Czech Republic, 31 May-2 June 2017; pp. 207-210, ISBN 978-1-5386-1988-9.

23. Rybansky, M.; Dohnal, F.; Hošková-Mayerová, Š.; Svatoňová, H. The impact of drainage on terrain UGV movement. In Proceedings of the IOP Conference Series: Earth and Environmental Science, 9th IGRSM International Conference and Exhibition on Geospatial \& Remote Sensing (IGRSM 2018), Kuala Lumpur, Malaysia, 24-25 April 2018.

24. Rybansky, M. Determination the ability of military vehicles to override vegetation. J. Terramech. 2020, 91, 129-138, ISSN 0022-4898. [CrossRef]

25. Hubacek, M.; Rybansky, M.; Brenova, M.; Ceplova, L. The soil traficability measurement in the Czech Republic for military and civil use. In Proceedings of the 18th International Conference of the ISTVS, Seoul, Korea, 22-25 September 2014; p. 8, ISBN 978-1-942112-45-7.

26. Talhofer, V.; Rybansky, M.; Bureš, M.; Šimková, K. The influence of spatial database quality on modelling of vehicle movement in terrain. In Proceedings of the 19th International \& 14th European-African Regional Conference of the International Society for Terrain-Vehicle Systems, Budapest, Hungary, 25-27 September 2017; pp. 1-15, ISBN 978-1-942112-49-5. 
27. Talhofer, V.; Bureš, M. The solution of the mobility model using the database of roads and terrain relief. In GIS Ostrava 2018 GIS for Support of Security and Crisis Management; Technical University of Ostrava: Ostrava, Czech Republic, 2018; ISBN 978-80-248-4166-3.

28. Nohel, J.; Stodola, P.; Flasar, Z. Model of the optimal maneuver route. In Path Planning for Autonomous Vehicles-Ensuring Reliable Driverless Navigation and Control Maneuver; IntechOpen Limited: London, UK, 2019; Available online: www.intechopen.com/ online-first/model-of-the-optimal-maneuver-route (accessed on 5 August 2020). [CrossRef]

29. Vala, M.; Braun, P. Military Wheeled Vehicles II: Theory of Movement of Vehicles. Chapter II. Textbook; Military Academy: Brno, Czech Republic, 1999.

30. Vala, M.; Žalud, Z.; Neumann, V. Theory and Construction of Military and Special Vehicles, Chapter III. Safety and Testing of Vehicles. Textbook; Faculty of Military Technology, University of Defence: Brno, Czech Republic, 2017; ISBN 978-80-7582-023-5.

31. Hlaváček, V. Evaluation of Dynamics of Vehicle Movement in the Terrain. Diploma Thesis, University of Defence, Brno, Czech Republic, 2017.

32. Hubacek, M.; Kovarik, V.; Talhofer, V.; Rybansky, M.; Hofmann, A.; Brenova, M.; Ceplova, L. Modelling of geographic and meteorological effects on vehicle movement in the open terrain. In Central Europe Area in View of Current Geography; Masarykova Univerzita: Brno, Czechia, 2016; pp. 149-159. ISBN 978-80-210-8313-4.

33. Hubacek, M.; Almasiova, L.; Brenova, M.; Bures, M.; Mertova, E. Assessing quality of soil maps and possibilities of their use for computing vehicle mobility. In Central Europe Area in View of Current Geography; Masarykova Univerzita: Brno, Czechia, 2016; pp. 99-110. ISBN 978-80-210-8313-4.

34. Hubáček, M.; Mertová, E. The influence of weather on soil properties and on terrain traverseability. In GIS Ostrava 2018: GIS pro Podporu Bezpečnosti a Krizového Řizení. Ostrava; VSB Technical University of Ostrava: Ostrava, Czech Republic, 2018; pp. 1-6. ISBN 978-80-248-4166-3.

35. Mertová, E. Comparison of the Soil map 1: 50,000 with the Special Purpose Database of Soils and possibility of its utilisation in Armed forces of the Czech Republic. Bachelor Thesis, University of Defence, Brno, Czech Republic, 2015.

36. Dohnal, F.; Hubacek, M.; Simkova, K. Detection of microrelief objects to impede the movement of vehicles in terrain. ISPRS Int. J. Geo Inf. 2019, 8, 101. [CrossRef]

37. Hofmann, A.; Hoškova-Mayerova, Š.; Talhofer, V.; Kovařik, V. Creation of models for calculation of coefficients of terrain passability. Qual. Quant. 2015, 49, 1679-1691. [CrossRef]

38. Hošková-Mayerová, Š.; Talhofer, V.; Otřísal, P.; Rybanský, M. Influence of weights of geographical factors on the results of multicriteria analysis in solving spatial analyses. ISPRS Int. J. Geo Inf. 2020, 9, 489.

39. Stodola, P.; Michenka, K.; Nohel, J.; Rybanský, M. Hybrid algorithm based on ant colony optimization and simulated annealing applied to the dynamic traveling salesman problem. Entropy 2020, 22, 884. [CrossRef] [PubMed]

40. Pokonieczny, K. Automatic military traverseability map generation system. In Proceedings of the 2017 International Conference on Military Technologies (ICMT), Brno, Czech Republic, 31 May-2 June 2017; pp. 285-292.

41. Pokonieczny, K. Methods of Using Self-Organising Maps for Terrain Classification, Using an Example of Developing a Military Traverseability Map. Dynamics in GIscience. Lecture Notes in Geoinformation and Cartography; Ivan, I., Horák, J., Inspektor, T., Eds.; Springer International Publishing: Cham, Switzerland, 2018; pp. 359-371.

42. Pokonieczny, K.; Rybansky, M. Method of developing the maps of passability for unmanned ground vehicles. In Proceedings of the IOP Conference Series: Earth and Environmental Science, 9th IGRSM International Conference and Exhibition on Geospatial \& Remote Sensing (IGRSM 2018), Kuala Lumpur, Malaysia, 24-25 April 2018; pp. 1-9. [CrossRef]

43. Heštera, H.; Pahernik, M. Physical-geographic factors of terrain trafficability of military vehicles according to Western World methodologies. Hrvat. Geogr. Glas. Geogr. Bull. 2018, 80, 5-31. [CrossRef]

44. Ciobotaru, T. Semi-empiric algorithm for assessment of the vehicle mobility. Leonardo Electron. J. Pract. Technol. 2009, 8, 19-30.

45. Vantsevich, V.V.; Lozynskyy, A.; Demkiv, L.; Klos, S. A foundation for realtime tire mobility estimation and control. In Proceedings of the 19th International \& 14th European-African Regional Conference of the ISTVS, Budapest, Hungary, 25-27 September 2017.

46. He, R.; Sandu, C.; Khan, A.K.; Guthrie, A.G.; Els, P.S.; Hamersma, H.A. Review of terramechanics models and their applicability to real-time application. J. Terramech. 2019, 81, 3-22. [CrossRef]

47. Iagnemma, K.; Dubowsky, S. Mobile Robots in Rough Terrain-Estimation, Motion Planning, and Control with Application to Planetary Rovers. Springer Tracts in Advanced Robotics; Springer: Berlin/Heidelberg, Germany, 2004; Volume 12, ISBN 978-3-540-40993.

48. Halatci, I.; Brooks, C.A.; Iagnemma, K. Terrain classification and classifier fusion for planetary exploration rovers. In Proceedings of the 2007 IEEE Aerospace Conference, Big Sky, MT, USA, 3-10 March 2007.

49. Reina, G.; Ishigami, G.; Nagatani, K.; Yoshida, K. Odometry correction using visual slip angle estimation for planetary exploration rovers. Adv. Robot. 2010, 24, 359-385. [CrossRef]

50. Reina, G.; Milella, A. Towards autonomous agriculture: Automatic ground detection using trinocular stereovision. Sensors 2012, 12, 12405-12423. [CrossRef]

51. Reina, G.; Bellone, M.; Spedicato, L.; Giannoccaro, N.I. 3D traversability awareness for rough terrain mobile robots. Sens. Rev. 2014, 34, 220-232. [CrossRef]

52. Braun, T.; Bitsch, H.; Berns, K. Visual terrain traversability estimation using a combined slope/elevation model. In Proceedings of the IEEE/RSJ International Conference on Intelligent Robots and System, Berlin, Germany, 22-26 September 2008; pp. 177-184.

53. Hrun, S.; Montemerlo, M.; Dahlkamp, H.; Stavens, D.; Aron, A.; Diebel, J.; Fong, P.; Gale, J.; Halpenny, M.; Hoffmann, G.; et al. Stanley: The robot that won the DARPA Grand Challenge. J. Field Robot. 2006, 23, 661-692. [CrossRef] 
54. Czech Pedological Society. Taxonomical Classification System of Soils. Available online: https://klasifikace.pedologie.czu.cz (accessed on 11 July 2020).

55. MGI. ÚDB Půdy: User 's Guide; Vojenský Zeměpisný Ústav (Military Geographic Institute): Prague, Czech Republic, 2000; Available online: https:/ /is.muni.cz/el/1431/podzim2005/Z8105/Databaze_pudy.txt (accessed on 11 July 2020).

56. Land Survey Office. DMR5G, Digital Terrain Model of the Czech Republic of the 5th Generation. Available online: http: / / geoportal.cuzk.cz (accessed on 15 February 2020).

57. Land Survey Office. ZABAGED ${ }^{\circledR}$, Fundamental Base of Geographic Data of the Czech Republic-Planimetric Components. Available online: https:/ / geoportal.cuzk.cz/(S(ygrlwkhyf0xukdtb1zrozhtr)) $/$ Default.aspx?lng=EN\&mode=TextMeta\&side= zabaged\&metadataID=CZ-CUZK-ZABAGED-VP\&mapid=8\&menu=241 (accessed on 15 February 2020).

58. Novák. Method for Determination of Imtraverseability of Soils. Technical Project. MPT 100; VZÚ: Praha, Czech Republic, 1995. 